\title{
8. Building and Maintaining Trust in Public Institutions: Is this possible?
}

\author{
Murray Petrie
}

Discussions of trust, integrity and social norms are a very important part of future-proofing the state. In this contribution I will assess New Zealand as a high-trust, high-integrity society, and identify some risks to trust and integrity. I will also discuss transparency, participation and accountability. The focus on transparency and participation has become increasingly prominent both internationally and domestically. The initial focus for most governments was on facilitating the disclosure of information. Now, it is more focused on active public participation in the design and implementation of public policies. I will also mention some specific areas for action in New Zealand, and some issues for discussion. I believe the case study of New Zealand will have some general lessons to be observed by Australia and other related countries.

A number of available indicators show that New Zealand is rated very highly in international measures of transparency and accountability. There is Transparency International's Corruption Perception Index. New Zealand has never ranked below fourth on that index, and for half of the time the index has been calculated, New Zealand has ranked first or equal first. Similarly, New Zealand ranks highly against indicators of open government and regulatory enforcement. On the Open Budget Index, New Zealand is second of 94 countries. In the area of freedom of the press, New Zealand is ranked sixteenth. These indicators present a general picture of New Zealand as a country of highintegrity and high-quality governance.

Now, what does the rest of the world look like? This map below is a visualisation of international Corruption Perception Index (CPI) scores. Those parts of the world that are in red or dark red are areas where corruption is perceived to be widespread or endemic. As indicated, corruption infects a large part of the rest of the world, including many countries that we trade with very actively, and increasingly so in Asia. 

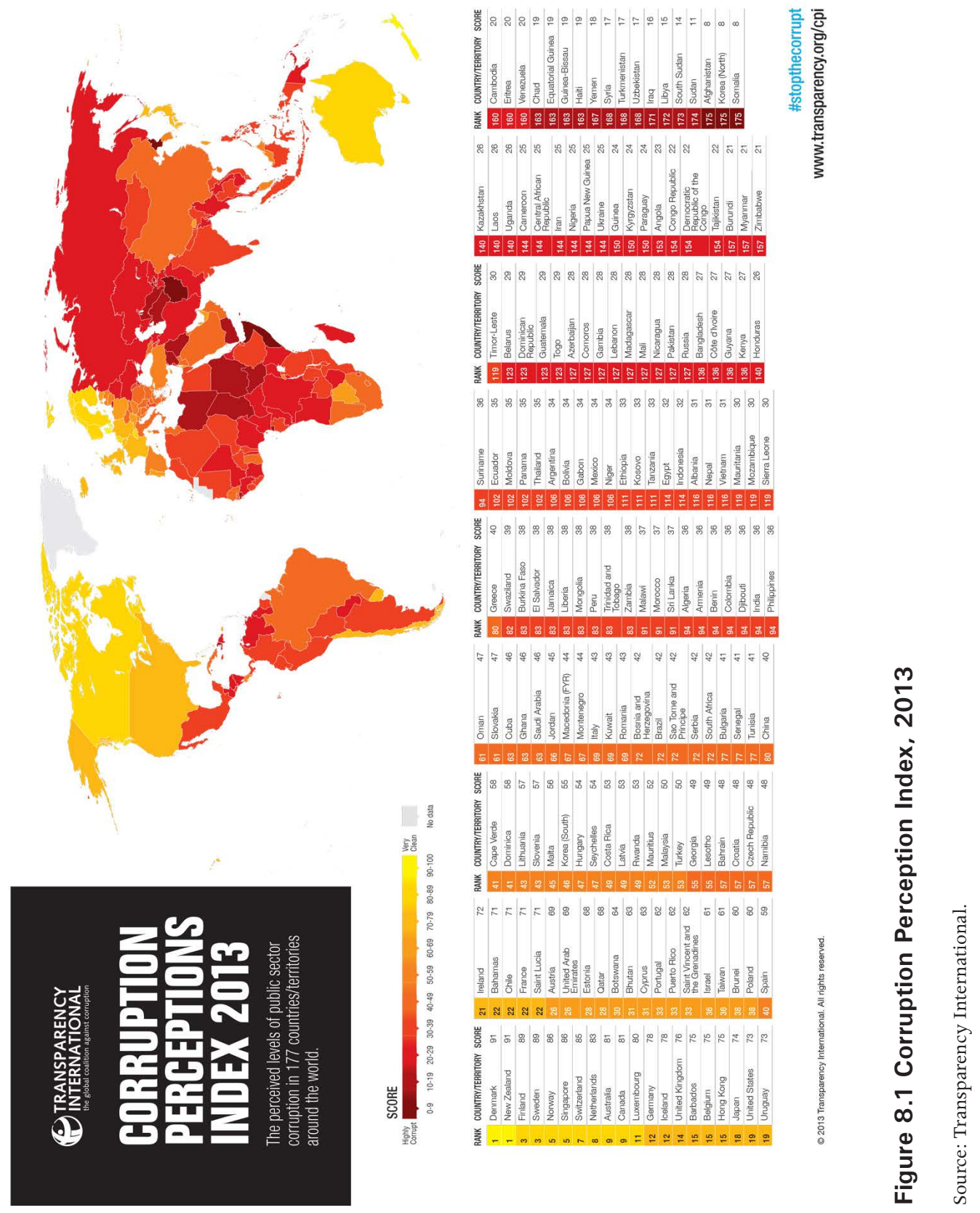
Australia is in a similar situation to New Zealand on the CPI. It lies in the second decile of the index. It operates a high-trust, high-integrity society in a world where corruption is essentially the norm. The relevance of the Australian and New Zealand examples is that both countries are designing mechanisms from which the rest of the world can learn.

It is important to understand why there is a lack of corruption in New Zealand. A large part of the reason for this is that the country has established and strong democratic institutions: an independent judiciary, a well-functioning parliament and watchdog institutions. It is also underpinned by stable social norms in a relatively small and cohesive society. It is, however, probably less cohesive than it has been in the past. The other countries that score very highly on the index are similarly small, advanced democracies, such as Denmark and Sweden. It is interesting, though, that Singapore has entered the top 10 on the CPI, having improved drastically in recent decades.

Let me explain why the issue of trust is such an important one. Trust is not a maudlin concept; it is not only a personal issue; rather, it is well known that societies with higher levels of trust achieve greater social, democratic and economic progress. One trend was evident when I returned to New Zealand after the Canterbury earthquakes after working overseas in countries where corruption is the norm. I attended a session at the Institute of Policy Studies on the Canterbury earthquake, during which presentations addressed questions such as how New Zealand's building standards affected the magnitude of destruction from the earthquake, and whether New Zealand needed to revisit its building standards. What struck me, coming from working overseas, was that in the whole discussion there was no single reference to whether or not the standards had been enforced; it was merely presumed they had been. The system had integrity. Moreover, there was no reference to the possibility that there was any corruption at any stage that exacerbated the damage caused by the earthquake. This is a good example of the social and economic value of a high-trust, high-integrity society. If one compares the different levels of death and damage caused by the Chilean and the Haitian earthquakes, the outcomes are staggering. Chile is a serious player, having a high quality of governance, while Haiti does not; and when both experienced a similar-sized earthquake the devastation was mild in Chile and catastrophic in Haiti. These two cases provide very dramatic illustrations of the consequences for societies of building or neglecting trust and integrity.

Our various social norms inform the rules of the game about what is desirable, permissible or tolerated. They are part of a wider set of mechanisms of social control, laws, incentives, information provision, nudging, and so on. They should be seen as part of that framework because the formal laws of the state, at the end of the day, require supporting social norms. And again, we see that 
in the examples from other countries: they have nice-looking legal frameworks that actually have very little impact and make very little difference on the ground because they are not supported by social norms. Voluntary compliance of the tax system is a very important example of a social norm that we in New Zealand may well take for granted.

There is also a range of social norms that underpins the operation of public institutions and the state, such as the constitutional convention of 'free and frank' advice that civil servants should provide to elected officials or the willingness to report wrongdoing. So if we consider this concept of trust and the related concept of legitimacy, three different forms of trust are often identified. Contractual trust relates to whether people adhere to their agreements. Competence trust refers to the faith citizens place in the competence of public officials and institutions; and goodwill trust describes the willingness to go beyond the minimum prescribed requirements of convention or law.

These are related to the two main dimensions of legitimacy. One is representative legitimacy, examples of which are how representative are our parliaments and whether we as citizens have the ability to access decision-makers. The second kind of legitimacy is performance legitimacy. This is an important element of effective public institutions that deliver public services-for example, maintaining the rule of law gives them a higher degree of perceived legitimacy.

Trust breeds more trust. The more one interacts with other people, the more they will begin to trust each other in economic relationships and personal relationships across the community. Only a relatively small number of countries, including New Zealand, experience this level of trust. Much of the rest of the world is trapped in a state where everybody assumes that everybody is out for themselves: why would someone pay taxes if they know no-one else is going to? Why would someone trust another person if it is likely they will be swindled? Those situations are hard to break out of because people refrain from the types of social interactions that might allow them to adjust their opinions. An interesting question for societies like New Zealand is whether our apparently high level of trust could unravel in the future? And if so, how, and how would we know? How might we detect what might be some quite subtle changes in the level of trust?

Cass Sunstein (1996), a US legal scholar who later entered the Obama administration as Administrator of the Office of Information and Regulatory Affairs, has argued that social norms can be surprisingly fragile. There can be large discrepancies between people's private judgments and their behaviour to conform to the norm. So, while they conform to the norm, privately they 
are questioning why they are doing so and asking if there is a way to change societal expectations about these norms. Sunstein (1996) points to changing norms around smoking as an example.

So what are some of the reasons why we might worry about the state of trust and integrity in New Zealand? What are some of the risks of corruption in New Zealand? These risks may include globalisation, increased cross-border linkages with countries where corruption is the norm, and trade-both export and import. One anecdote that illustrates this is where New Zealand exports to highcorruption countries. Siemens, the large German electronics and engineering company, appointed their star export manager as chief executive. He had been operating overseas. A couple of years later, the board was horrified to find he had started paying bribes in Germany. Siemens had to fire him, which was immediately damaging to the corporate image of the company. As such, there was a realistic risk that behaviours that are seen as normal overseas might become internalised through exports, through inward and outward investment, and through increasing immigration from countries where corruption is the norm. People have different views about whether it is legitimate or not to pay or to accept a bribe.

Money-laundering is another threat to building trust in public institutions. Front companies and shell companies have been recently common in New Zealand: it is very easy to set up a company in New Zealand, and perhaps monitoring mechanisms for impropriety are too lax. Organised crime is an increasing problem in New Zealand as it is globally. Professor Bob Gregory, at Victoria University, and two colleagues have published an interesting article on corruption in New Zealand that asks whether the rapid increase in income inequality in New Zealand could change prevailing attitudes around trust, integrity and legitimacy in a way that might cause some people to become more likely to commit fraud or corruption.

Another point relates to the rebuilding process following the Christchurch earthquakes. The earthquakes in Christchurch were a major shock to the economy and to New Zealand society. How this relates to the global trends of corruption during the rebuilding that follows natural disasters is interesting. Transparency International (TI) has done a lot of work in post-disaster situations around the world, and found that corruption often increases in these situations. Normal procurement practices are often changed because of the perceived need to respond rapidly to the size of the natural disaster. Insurance fraud can easily increase. So we should be vigilant about this risk in the rebuilding process in Christchurch.

The academic Robert Klitgaard (1988) has conceived a definition of corruption that is useful when thinking about which specific parts of the public sector are 
particularly prone to corruption and fraud. He says 'corruption is the coincidence of monopoly and discretion, minus accountability'. That points generally to the importance of competition and contestability. It is imperative to remove the level of monopoly discretion in the hands of public servants with strong regulations. The police, globally, are the public institution to which people pay the most bribes. This is verified by Transparency International's global corruption barometer. We are lucky in New Zealand to have a less corrupt police force, but it is nevertheless an institution about which the public sector should remain vigilant. New Zealand has experienced cases of corruption in a wide range of government departments, including the Immigration Department, the Customs Department and the Corrections Department. The judiciary, however, which is typically a corrupt institution around the world, ranks low on the list of corruption in New Zealand.

I consider we are naive about corruption in New Zealand. The country is transparent and honest in its domestic and international dealings; this increases the possibility for some to take advantage of New Zealand, which is why we should support the international conventions that criminalise the payment of bribes by private business. It is in our narrow and broader interests to support those initiatives. We are probably not very good at identifying corruption compared with others who have been doing it for a very long time.

At times, New Zealanders seem oblivious to conflicts of interest. Public lawyer Mai Chen, who is a member of Transparency International New Zealand, has described how she is at times astounded at how experienced executives are oblivious to a conflict of interest. Being a small country is often seen as an advantage in terms of trust and social norms and lack of corruption. It can also be a problem if we are not alert enough to the fact that we often know the people we are dealing with on the other side of a transaction.

There are also some latent weaknesses in our high CPI rating. First, the Corruption Perception Index measures only perceptions, not actuality. Moreover, these are the perceptions of some experts and businesspeople. Hence, the CPI is really attuned to focusing on the interface between the business sector and public officials, and whether bribes are expected to be paid to receive government services such as getting goods off the wharf, a regulatory approval and so on. Apparently, two of the six surveys that make up New Zealand's score on the CPI are by just one expert. This obviously raises the risk of bias. Perhaps more importantly, the focus of the CPI is on bribery, not on other forms of corruption, such as nepotism or political corruption. Indeed, some New Zealanders do admit to paying bribes. In a survey conducted in 2010, 3.6 per cent of respondents claimed that they or a member of their household had paid a bribe to an official of a public institution in the previous 12 months. This figure surprised a number of us. Has corruption in New Zealand increased in the past three years? 
Seventy-three per cent said 'yes'. These figures are consistent with some other survey evidence. For instance, the State Services Commission has conducted an Integrity and Conduct Survey of more than 8000 respondents. Fifteen per cent of respondents reported observing illegal conduct in the previous year. Four per cent observed giving or accepting inappropriate payments or perks. Five per cent observed inappropriate alteration of documents.

The Office of the Auditor-General should be commended for taking the initiative and conducting a public sector fraud survey in 2011. Generally, the results were pleasing; however, one surprising and worrying statistic was that 23 per cent of the respondents said they had seen internal fraud in the past two years. Also worrying is the small number of people reporting wrongdoing under the Protected Disclosures Act. Simply put, there may be more corruption occurring than is being reported. The lack of reporting occurs despite a number of surveys showing that New Zealanders express willingness to report unethical behaviour. One interesting speculation made in the aforementioned article by Bob Gregory and colleagues is that the increase in reporting of corruption might, in some way, desensitise people to the undesirability of committing fraud and corruption.

Another area of concern is that there is a diverse range of norms in New Zealand. The 1998 New Zealand study of values, which is a bit dated, nonetheless reveals some interesting statistics. The survey focused on the ethnicity of respondents as a way of understanding differences in their attitudes to norms and values. Once respondents were asked to self-identify their ethnicity, a question posed was whether it was unjustifiable to accept a bribe. Ninety-one per cent of Europeans said 'yes', but only 72 per cent of Maori said 'yes'. On the question of whether claiming unentitled benefits was unjustifiable, 83 per cent of New Zealanders said 'yes', while less than 50 per cent of Pacific peoples said 'yes'. To the question of whether democracy in New Zealand was ineffective due to poor decision-making, most New Zealanders said 'no'; however, 44 per cent of those who had only a primary level of education said 'yes'. So the perceived effectiveness of our democracy remained low for certain strata of our society. When asked whether the Treaty of Waitangi should be abolished, 47 per cent of people in the lowest income bracket said 'yes'.

The Global Corruption Barometer has measured which institutions in New Zealand are perceived as being most corrupt. It is interesting that political parties and the national Parliament enjoy widespread cynicism and fairly high levels of perceived corruption. This is true at the global level as well. It is also true in Australia. The major difference between New Zealand and Australia here is the police force. New Zealand's police force has been measured as being low on the global corruption scale. In Australia, conversely, the police are up the top of the scale and are seen as being as corrupt as political parties and the national Parliament. The major prescriptive issue for New Zealand is to consider what 
actions it should now take to (re)build trust and integrity and to reduce risks. The Government has to be more proactive in fostering positive social norms. To combat the increased and often more sensational media coverage of corruption, public institutions need to do more to reinforce the fact that most people observe the law and that corruption is generally rare in New Zealand.

Some interesting UK evidence reports on the levels of compliance with their provisional tax system. The United Kingdom conducted a randomised control trial in which they mailed 140000 letters to provisional taxpayers who had failed to make their first payment on time. One reminder letter notified the recipient that they had to pay their tax within six weeks or face punishment. The alternative letter in this trial included data on levels of voluntary compliance with the provisional tax system. Those receiving the second letter, which gave data on voluntary compliance in their immediate locality, recorded an increase of 15 percentage points in the number of people who paid before the six-week deadline. This is an impressive result and it raises the possibility that we need to be thinking more about using positive framing and positive reinforcement to offset the negative perceptions generated by the increased publicity of illegal behaviour.

Increased public participation is an important way of building greater trust in public institutions. In advanced democracies this is done frequently, but the international norms are starting to move beyond disclosure to focus very much on concrete, active, direct participation by citizens, in between elections, in policy design and implementation. One relevant example comes from the Global Initiative for Fiscal Transparency (GIFT). GIFT is a new, multi-stakeholder initiative that aims to promote greater transparency, participation and accountability. Its stakeholders are the International Monetary Fund (IMF), the World Bank, some global NGOs, plus some governments. A major principle of the GIFT initiative is that citizens and all non-state actors should have the right to participate directly in public debate over the design and implementation of fiscal policies.

Increasing public participation includes practices of informing, which is basically disclosure, consulting, involving, collaborating and, finally, empowering. One example of a measure taken to increase public participation is social auditing. This is becoming popular globally, but particularly in developing and middleincome countries in which civil society is increasingly involved in monitoring the implementation of a government investment project. Civil society could be monitoring the delivery of public services by using mobile phone technology, since the cost of new communication technologies has radically reduced in recent years. Hence, social audits are something we should think about as part of the social verification mechanisms in New Zealand. 


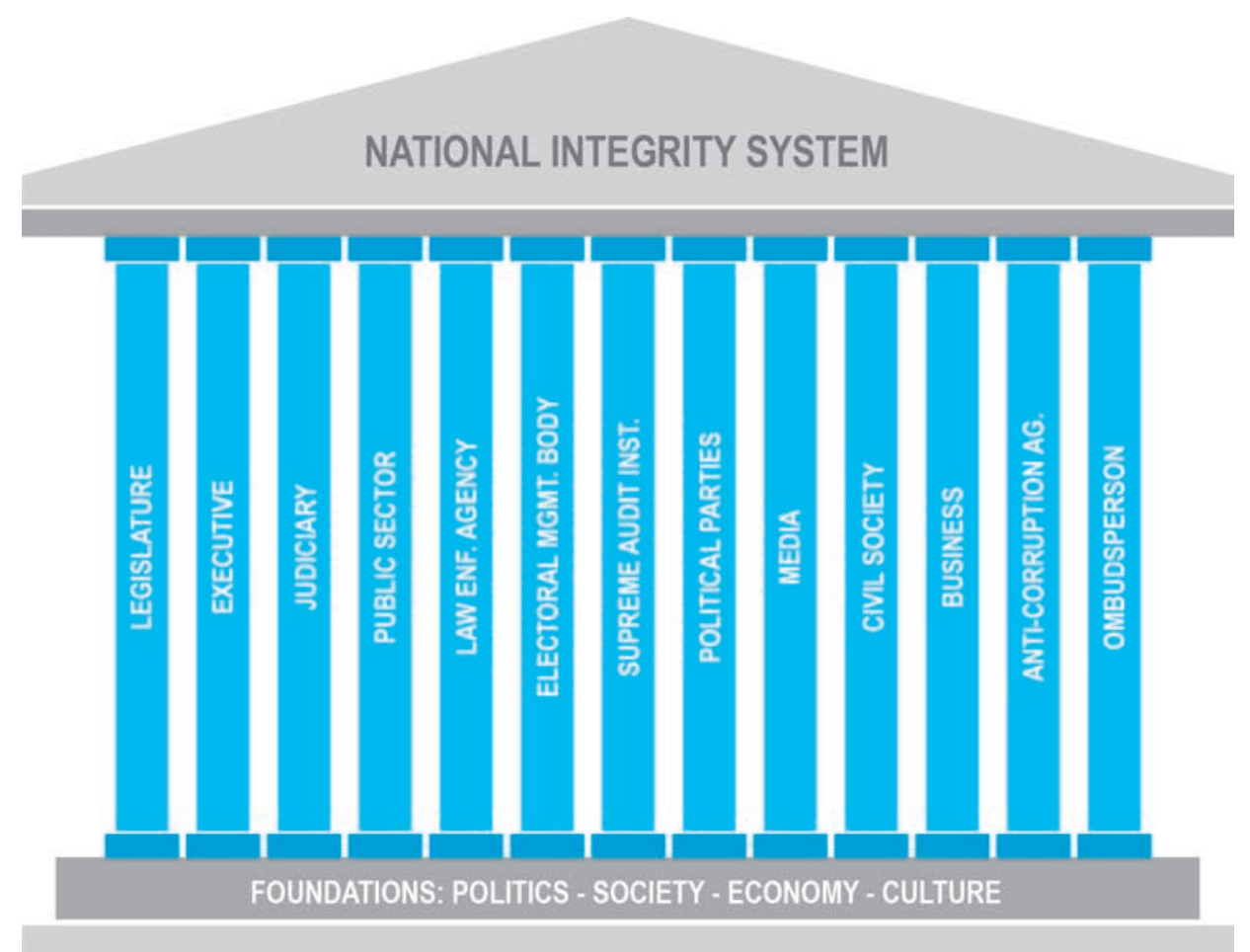

\section{Figure 8.2 Pillars of the National Integrity System}

Source: Transparency International.

A further example of initiatives to increase public participation is participatory budgeting. The Swiss have been doing it for a very long time. Now, however, this trend is increasingly occurring at sub-national and local government levels around the world, albeit from a low base. In some countries this has allowed for the possibility of actually putting together packages of tax increases along with specific spending proposals, and, as they are doing in some countries such as Brazil, putting aside a small amount of money for citizen decision on how it is to be spent.

The creation of independent fiscal councils is another measure to be considered. Recent discussion about establishing one of these in New Zealand has become more noticeable. We have some real problems around the level of public participation in the setting of macro fiscal policy, and how much the public debt and the deficit should be and how we should be spending our money in a sectoral sense. An independent fiscal council would stand in stark contrast with and be a major improvement to New Zealand's current fiscal review process. At the moment, the only monitoring of fiscal policy in the country occurs in the single chamber of Parliament and the finance and expenditure committee, which 
is chaired by a member of the governing party. That committee has a budget to access independent advice, but it has never used it to retain advice on fiscal policy. Moreover, last year, the finance and expenditure committee received just two public submissions on the Government's budget policy statement; the Government does not respond to these submissions.

Citizen co-production offers a compelling avenue for increasing public participation. Again, an anecdote serves to illustrate the benefits of this process. There was a retired fireman sitting in a cafe in his home city in California when suddenly an ambulance pulled up next door. The paramedics rushed in to a restaurant and a group of people followed them in. The retired fireman asked the paramedics what had happened, and they told him that a man had just died from a heart attack. The fireman is rueful when he is told this, as he had been sitting in this cafe next door to the restaurant and he was trained in delivering cardiopulmonary resuscitation (CPR) that could have saved that man's life. In the aftermath of this event, the retired fireman submitted a proposal to his local council, which has now been adopted. The council has put together a register of everybody in the city who is trained in CPR. They compiled their mobile phone numbers. Now, when there is an emergency where it will take the ambulance some time to arrive at the scene, the council sends a text message to everybody on that list to see if there is anyone in the area who can give CPR. This is a good example of the kind of new public participation and co-production that is enabled by new technology.

The previous diagram (Figure 8.2) depicts an analytical framework developed by Jeremy Pope of Transparency International Berlin for a National Integrity System. Pope, the current Human Rights Commissioner, is strongly associated with this framework because he was the founding managing director of TI. The idea is that the state of integrity and transparency, and trust and effectiveness of government, is associated with how the different pillars in the national integrity system function. This includes the legislature, the executive, the judiciary, key watchdog institutions such as the auditor-general and the ombudsman, business, civil society, the media, political parties and so on. This is a framework that is a very useful way to think about assessing the state of integrity and governance.

TI New Zealand is about to commence a new systemic study. It will have been nearly 10 years since we did the last one. The study will assess New Zealand against international best practices in transparency, participation and accountability, and anticorruption. The project has received financial support from the Office of the Auditor-General and the State Services Commission, and we are approaching other agencies. The Department of Prime Minister and Cabinet is supportive. The release of the new study is intended to coincide with the centenary of the Public Service Act, which was passed in 1912 and implemented in April 1913. So it is a salient time to launch a new focus on transparency and accountability in New Zealand. The approach will be collaborative and consultative. The objective is 
to test New Zealand's perception of itself, as a country with high standards of transparency and accountability, free of and at low risk of corruption, and to identify areas where action is needed to strengthen transparency, accountability, and participation, and to kick-start the necessary changes. (Transparency International 2013).

So what do I think are some specific areas for action? Well, we need to invest more resources in diagnosis. The national integrity study is an important example; however, there need to be more public surveys about attitudes towards compliance and voluntary compliance, as well as towards norms of trust and norms against bribery. We need to probe New Zealand's high rating. New Zealand should inquire more deeply about whether it faces risks of corruption and fraud.

I would argue that another important feature that is lacking in New Zealand is an ethics code for MPs. This would improve the legitimacy of Parliament. New Zealand needs more transparency in lobbying. The transparency of political parties is also important. I think of financing issues that have been brought to the fore in the past five years, but are still not properly settled. The boundary between political parties and the public purse needs far more transparency. This is partly related to the Official Information Act, which does not apply to the administration of Parliament. There needs to be more focus on areas of highest risk, utilising the framework of monopoly and discretion, and we need a more results-focused public service.

The United Kingdom has been putting a huge amount of effort into this in recent years. And again, while I generally do not think an anecdote constitutes an argument, I believe this one is illustrative of some of the things we need to be thinking about in New Zealand. In the United Kingdom, a leading heart surgeon led an initiative, saying 'we need to publicise the mortality rate of patients against individual heart surgeons'. That was agreed within the medical profession and was put into place, I think, about two years ago. The mortality rate has come down significantly in the United Kingdom since that happened. Such initiatives have not been thought about much in New Zealand, and we really do need to do that.

The destruction of the environment is a concern for the public. This stems partly from what the Government does, and obviously, also what the private sector does. This leads to the regulatory function. We need to think about triple bottom-line reporting for government. This discussion has been brought up at the global level. One of the principles of the GIFT initiative states: 'Governments should strive to report the economic, financial and environmental impacts of what they do' (GIFT 2012). We need to do a much better job of that in New Zealand. We could, again, lead the world, if we take it seriously. 
Our private sector seems remarkably complacent. Many people within the private sector do not know that since 2000 it is a crime to bribe a foreign public official. So, if you are offshore and you are an exporter, and you are trying to get your goods off the wharf, or whatever it might be, you are subject to New Zealand criminal law if you pay a bribe. Some New Zealanders working in overseas markets think they can avoid the legal punishments if they use an intermediary to pay the bribe; however, that is not the case: they are still breaking the law. It is important to conduct more training and raise awareness of the role of professional integrity. TI New Zealand is starting to work more closely with professional service firms and trying to engage them in raising awareness of corruption and bribery in New Zealand.

In the longer term, introducing mandatory civics education in schools is crucial to our objective. New Zealand urgently needs to educate its young people about the strong public and democratic institutions that we all take for granted. They should understand how our public system, our constitutional arrangements, our Parliament, our executive and our judiciary function and interact.

New Zealand should take more steps to abide by international law on corruption. In 2003, New Zealand signed the United Nations Convention against Corruption (UNCAC); however, it has still not ratified it. There are no defensible reasons for not doing so. Ratifying the convention would necessitate a small number of legal tweaks to New Zealand legislation. The ratification decision has been sitting in select committee for a couple of years, and we really do need to take that final step and ratify it. Ratifying it would require the Government to come up with a new national anticorruption strategy, and to do that in a widely consultative fashion.

Finally, New Zealand should join the Open Government Partnership. This is one of US President Barack Obama's foreign policy initiatives. The United States and Brazil have led this, and the United Kingdom is one of the founding members. It is a new club of countries which are committed to open government. There are a few low-level entry requirements: the main requirement for members is that they have to bring to the table and develop new initiatives that involve civil society and the private sector. New Zealand should seriously consider joining the Open Government Partnership to look at what is going on in other comparable countries such as the United Kingdom. It would be a way of signalling and cementing greater transparency and accountability in this and other areas.

\section{References}

Global Initiative for Fiscal Transparency (GIFT). 2012. High-Level Principles on Fiscal Transparency, 1 November. Available from: <http://fiscaltransparency. net/2012/11/high-level-principles-on-fiscal-transparency/>. 
Klitgaard, R. 1988. Controlling Corruption (Berkeley: University of California Press).

Sunstein, C. 1996. 'Social Norms and Social Roles' Columbia Law Review, 96(4): 903-68.

Transparency International. 2013. 'Integrity Plus NIS Assessment: Taking High Trust to all Facets of New Zealand Society', Transparency Times, January. Available from: <http://www.transparency.org.nz/docs/2013/TransparencyTimes-January-2013.pdf?PHPSESSID=08d6e857f537407d2cd9d8397ba0edb5 > . 
This text taken from Future-Proofing the State: Managing Risks, Responding to Crises and Building Resilience, edited by Jonathan Boston, John Wanna, Vic Lipski and Justin Pritchard, published May 2014 by ANU Press, The Australian National University, Canberra, Australia. 